\title{
Knowledge, Attitude and Practice towards Evidence Based Practice in Post Graduate Physiotherapy Students
}

\author{
Chaitali J. Bhatt ${ }^{1}$, Megha S Sheth ${ }^{2}$ \\ ${ }^{1}$ MPT, Community Health and Rehabilitation, SBB College of Physiotherapy, Ahmedabad, Gujarat, India \\ ${ }^{2}$ Lecturer, Community Health and Rehabilitation, SBB College of Physiotherapy, Ahmedabad, Gujarat, India
}

Corresponding Author: Chaitali J. Bhatt

\begin{abstract}
Background: Evidence Based Practice (EBP) includes integration of best available research, clinical expertise, and patient values and circumstances related to patient and client management, practice management. EBP approach can lead to enhanced quality of whole health care and is important to professional development of physiotherapists. The purpose of the study was to assess the level of knowledge, attitude and practice of Evidence-Based Practice among Physiotherapy students.

Methodology: One hundred and thirty-two Post-Graduate physiotherapy students of Gujarat University were included using convenience sampling. Participants were given the Evidence-Based Practice Profile (EBP2) to complete. The Evidence-Based Practice Profile (EBP2) takes 10-12 minutes to complete and consists of a total of 58 items, each using a 5-point Likert scale and other characteristics. The questionnaire includes five domains. Descriptive Analysis was done in Microsoft excel.

Results: The EBP2 was completed by 100 subjects (Student response rate:-75.75\%). 92 were females and 8 were males with mean age $23.27 \pm 1.15$ years. Mean total domain score (maximum) in Relevance was 57.57 \pm 7.38 (70), Terminology was 59.74 \pm 10.6 (85), Confidence was $37.29 \pm 9.64$ (55), Sympathy was $19.3 \pm 3.89$ (35), Practice was $26.38 \pm 7.95$ (45).

Conclusion: There was a fair knowledge (Relevance, Terminology) of EBP, fairly positive attitude (Sympathy, Confidence) and fair practice (Practice) of EBP among post graduate students of Gujarat University.

Implication: There is a need to educate students at undergraduate level to improve practice of EBP at post graduate (professional) level and progress the profession's approach to developing, using and promoting research and its contribution to generating new evidence, knowledge transfer and service improvement.
\end{abstract}

Keywords: Evidence Based Practice; Physiotherapy; Post Graduate Students

\section{INTRODUCTION}

Evidence-based practice (EBP), which originates from evidence-based medicine, has been described as 'the conscientious, explicit, and judicious use of current best evidence in making decisions about the care of individual patients. Evidence Based Practice (EBP) includes integration of best available research, clinical expertise, and patient values and circumstances related to patient and client management, practice management, and health policy decision-making. ${ }^{[1]}$

Sackett et al originally described the fundamental principles and the 5 steps of Evidence-Based Practice follows:

1. Ask: Formulating a research question,

2. Acquire: Knowledge related to search engines/ databases, Literature search, 
3. Appraise: Inclusion of Levels/hierarchy of evidence, Types of study designs, Types of validity \& reliability, Tools of critical appraisal, Inclusion of Statistical methods,

4. Apply: Application of evidence in clinical decision making,

5. Assess: Ability to self reflect on how well the previous four steps were performed. ${ }^{[2]}$

EBP approach can lead to enhanced quality of whole health care. That is important to professional development of physiotherapists. In the recent times, the Physiotherapy profession has been undergoing a period of change as a result of pressure from different health professional groups. In order to meet these challenges Physiotherapists (PTs) have been encouraged to prove the effectiveness of their interventions through scientific evidence known as evidence based Practice $^{[3,4]}$ By incorporating Evidence based practice in bachelors' curriculum, it will help to implement EBP at their Postgraduate or clinical level for clinicaldecision making.

Because of the publication of the Sicily statement, ${ }^{[1]}$ there has been greater attention paid to EBP training in entry level education (Bachelor degrees or equivalent). Glasziou recommended that, EBP training should be introduced early, and embedded and applied throughout entry-level training. ${ }^{[5]}$ In theory, the training for EBP should 'future-proof' graduates with the life-long learning skills required for making evidence-based health care decisions. ${ }^{[1]}$ The World Confederation for Physical Therapy (WCPT) believes that, Physical therapists have a responsibility to ensure that the management of patients/clients, carers and communities is based on the best available evidence. They also have a responsibility not to use techniques and technologies that have been shown to be ineffective or unsafe. $^{[6]}$ EBP is still not a part of the curriculum in many universities, but is part of few universities of Gujarat in Undergraduate and postgraduate Courses.
Studies in India and especially in Gujarat are few.

Dawes et al. suggest that learning has three components; knowledge, attitudes and skill, and out of these, the development of attitudes is the most difficult and even problematic as attitudes are "caught, not taught" at the point of patient contact where students learn to incorporate theory into practical skills for patient care. ${ }^{[1]}$ EvidenceBased Practice Profile (EBP2) questionnaire, a self-reported questionnaire that examines self-perceived EBP knowledge, attitude and practice was used. The questionnaire has demonstrated very good reliability. The validity findings show promise in the application of the questionnaire for assessing and monitoring changes in the characteristics associated with an EBP profile at an individual and undergraduate curricula level and potentially beyond, when graduates move into the workforce. ${ }^{[7]}$

The purpose of the study was to assess the level of knowledge, attitude and practice of Evidence-Based Practice and correlate knowledge, attitude and practice among Post Graduate Physiotherapy students.

\section{METHOD}

An Observational study was conducted in which 132 Post Graduate students of First and Second year of physiotherapy colleges of Gujarat University were included using convenience sampling. Students unwilling to participate were excluded. Permission to conduct the study was obtained from the head of the institute. Participants were explained the study and given the questionnaire to fill out. One hundred students completed the questionnaire.

The Evidence-Based Practice Profile Questionnaire (EBP2) ${ }^{[7]}$ was used in the study after taking the permission from the author. Evidence-Based Practice Profile (EBP2) is a self-reported questionnaire that examines self-perceived EBP knowledge, attitude and practice. The questionnaire has 
demonstrated very good reliability. The validity findings show promise in the application of the questionnaire for assessing and monitoring changes in the characteristics associated with an EBP profile at an individual and undergraduate curricula level and potentially beyond, when graduates move into the workforce. ${ }^{[7]}$ The EBP2 had been previously evaluated for reliability and validity (ICCs 0.77-0.94, convergent validity $\mathrm{r}=0.52-0.80$, discriminative validity ANOVA $\mathrm{p}<0.001$ to 0.004). ${ }^{[7]}$

The questionnaire required 10-12 minutes to complete. The questionnaire included 74 items all of which used a 5point Likert scale, with a further few items which address demographic characteristics and prior exposure to EBP training. There are five domains of questionnaire. The first 58 items related to one of five domains of EBP (Relevance, Terminology, Confidence, Practice, and Sympathy). Definition of these domains and item numbers are given in table 1. There were 16 additional nondomain items that described environmental and personal characteristics that might act as barriers or facilitators to EBP. Scoring of individual domain item scores were aggregated to give a domain score (5-point Likert scale, minimum score of 1 and a maximum score of 5 per item). For scoring, sympathy domain it needs to have Likert score reversed. Space was provided in the questionnaire for the addition of comments.

\begin{tabular}{|l|l|l|l|}
\hline \multicolumn{3}{|c|}{ Table 1: Description of Domains and its item number of Evidence Based Practice Profile (EBP2) } \\
\hline $\begin{array}{l}\text { EBP2 } \\
\text { Domain }\end{array}$ & Item Description & $\begin{array}{l}\text { Item } \\
\text { Numbers }\end{array}$ & $\begin{array}{l}\text { Likert scale label (1-5) } \\
\text { Lowest -Highest }\end{array}$ \\
\hline Relevance & $\begin{array}{l}\text { Refers to the value, emphasis or importance placed on } \\
\text { EBP }\end{array}$ & $1-14$ & $\begin{array}{l}\text { Not at all true - Very true } \\
\text { Strongly disagree - Strongly agree }\end{array}$ \\
\hline Terminology & $\begin{array}{l}\text { Refers to an understanding of common research and } \\
\text { statistical terms }\end{array}$ & $\begin{array}{l}\text { Never heard the term - Understand and could } \\
\text { explain to others }\end{array}$ \\
\hline Confidence & Refers to a perception of ability with EBP skills & $48-58$ & Not at all confident - Very confident \\
\hline Practice & Refers to the use of EBP in clinical situations & $39-47$ & Never - Daily \\
\hline Sympathy* & $\begin{array}{l}\text { Refers to the compatibility of EBP with professional } \\
\text { work }\end{array}$ & $15-21$ & Strongly disagree - Strongly agree \\
\hline
\end{tabular}

Knowledge includes Relevance and Terminology, Altitude includes Sympathy, Confidence and Practice.

Descriptive Analysis was done in Microsoft excel. Higher scores indicate better awareness. Spearman correlation was used to correlate between domains.

\section{RESULTS}

The EBP2 was completed by 100 subjects. Student response rate was $75.75 \%$ of which 92 were females and 8 were males. Year of passing graduation ranged between 2014-2018. Demographic data is shown in Table 2.

\begin{tabular}{|l|l|}
\hline \multicolumn{2}{|c|}{ Table 1: Demographic data of students } \\
\hline Gender & Mean \pm SD \\
\hline Females & 92 \\
\hline Males & 8 \\
\hline Total & 100 \\
\hline Age (in years) & $23.27 \pm 1.15$ \\
\hline Education level & \\
\hline $1^{\text {st }}$ year & 50 \\
\hline $2^{\text {nd }}$ year & 50 \\
\hline
\end{tabular}

$23 \%$ of the students reported that they had undertaken EBP training. Courses included in form of short course of 10-20 hours, a single lecture of 1-3 hours and weekend course of 3-10 hours which is shown in the Graph 1.

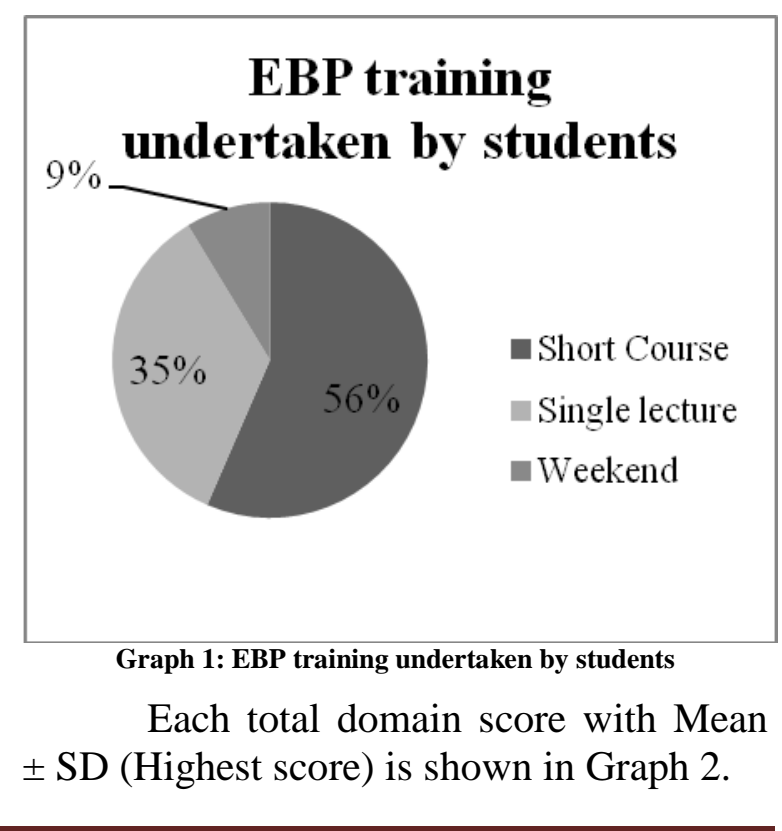


Chaitali J. Bhatt et.al. Knowledge, attitude and practice towards evidence based practice in post graduate physiotherapy students.

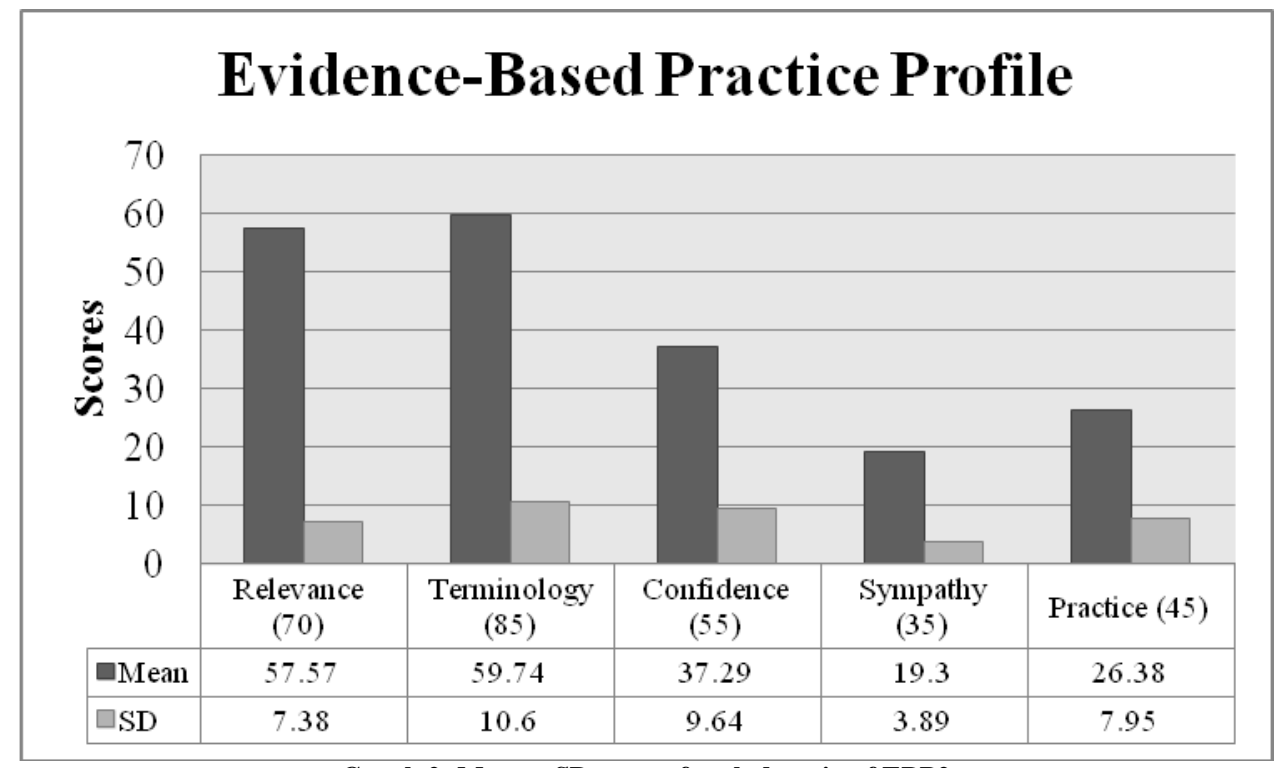

Graph 2: Mean \pm SD score of each domain of EBP2

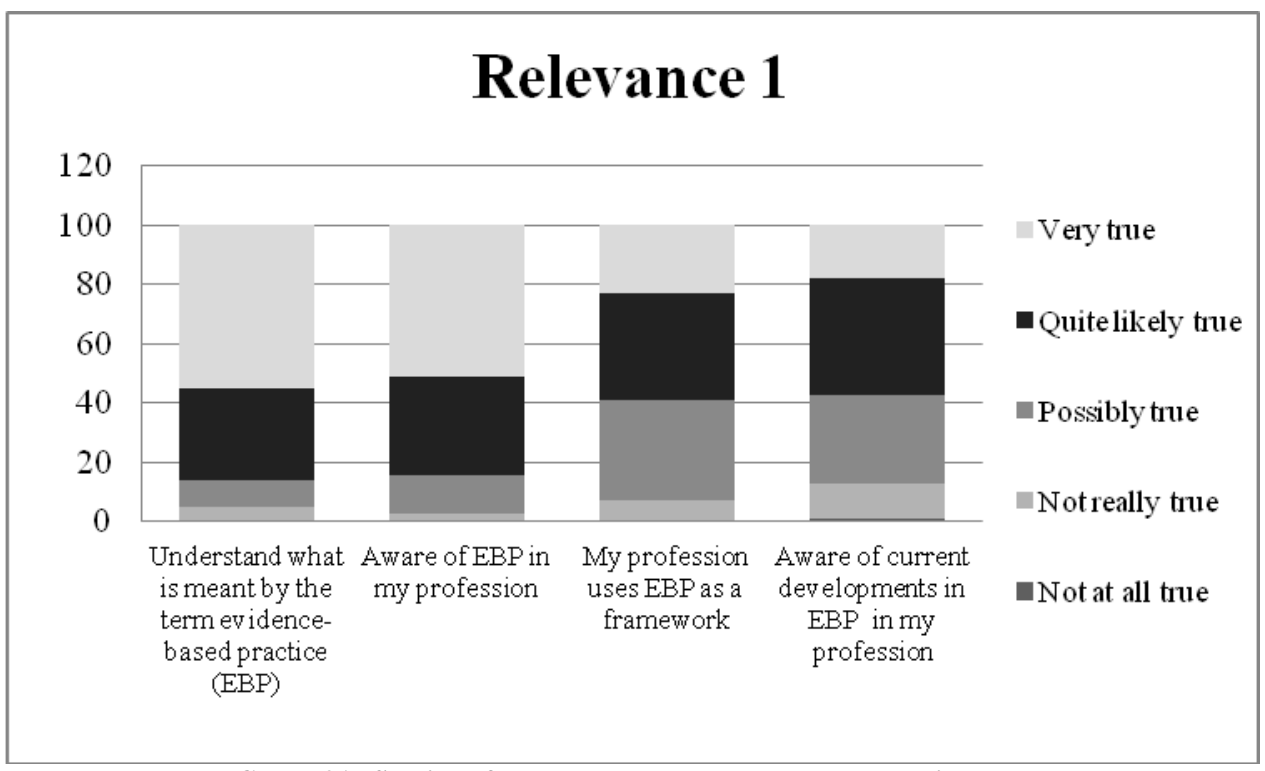

Graph 3A: Scoring of responses related to Relevance domain score

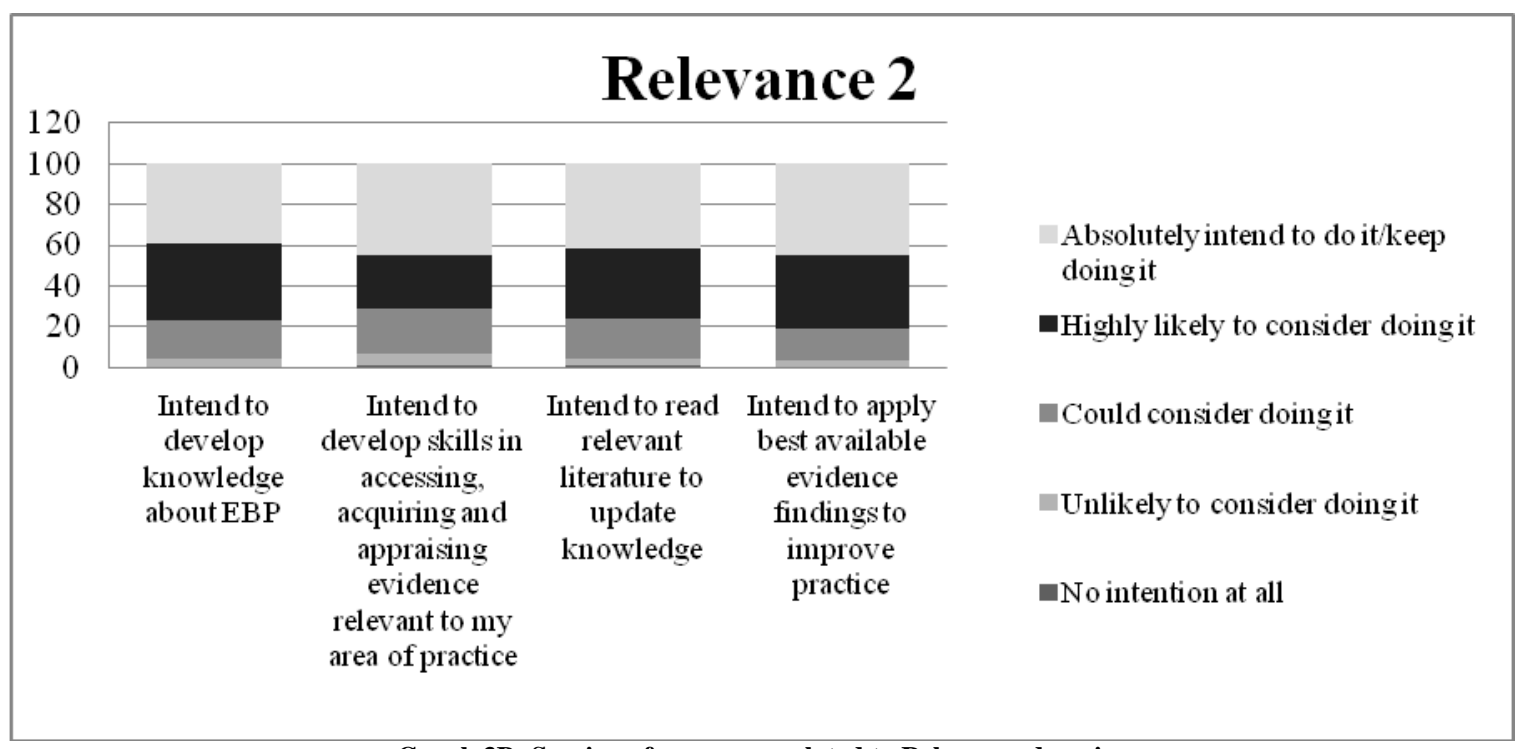

Graph 3B: Scoring of responses related to Relevance domain score 
Chaitali J. Bhatt et.al. Knowledge, attitude and practice towards evidence based practice in post graduate physiotherapy students.

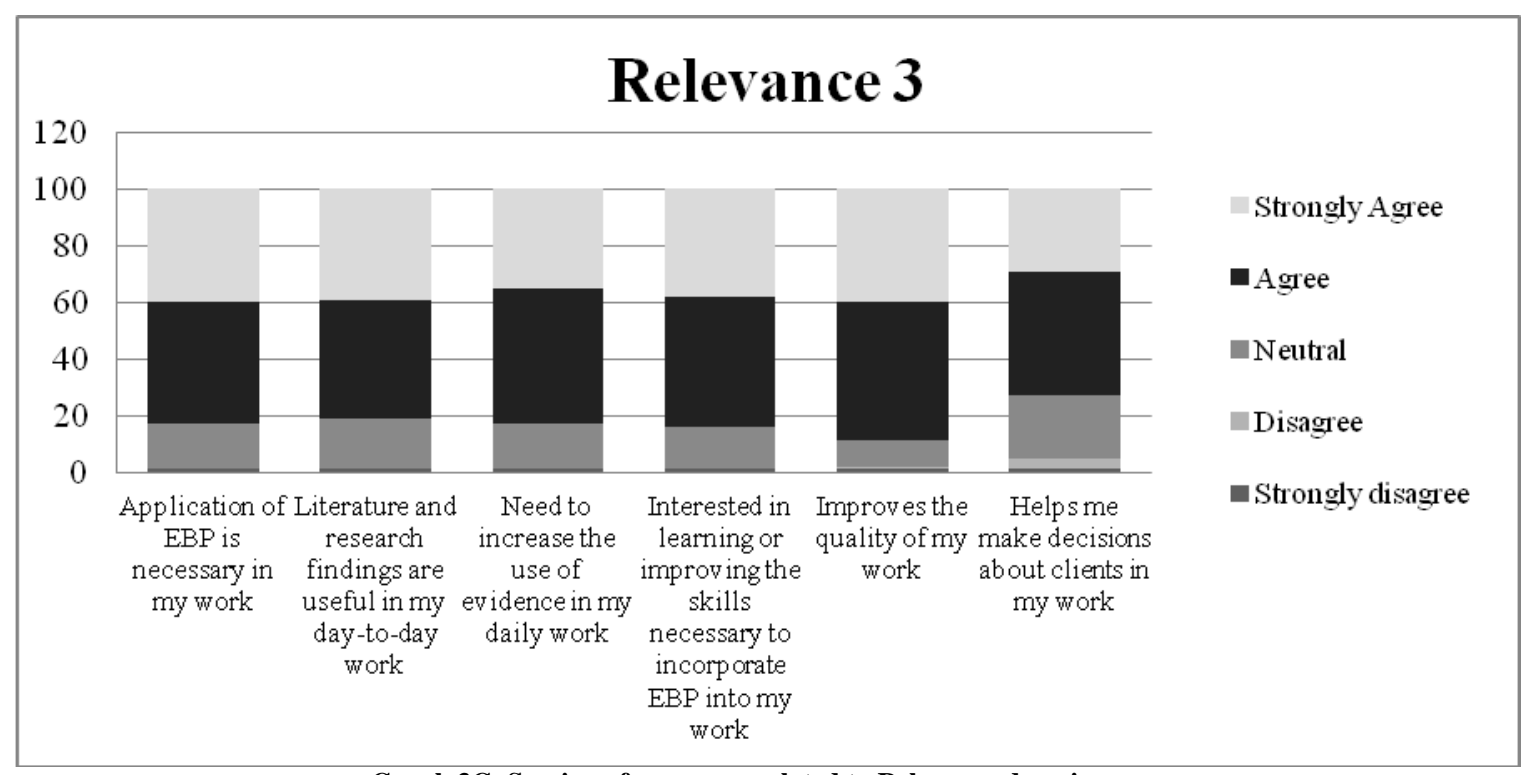

Graph 3C: Scoring of responses related to Relevance domain score

Graph 3A, 3B and 3C shows the Scoring of responses related to Relevance domain of $1^{\text {st }}$ and $2^{\text {nd }}$ year PG students.

Graph 4 shows Understanding of research terminologies, and percentages students who responded never heard and understand terms completely.

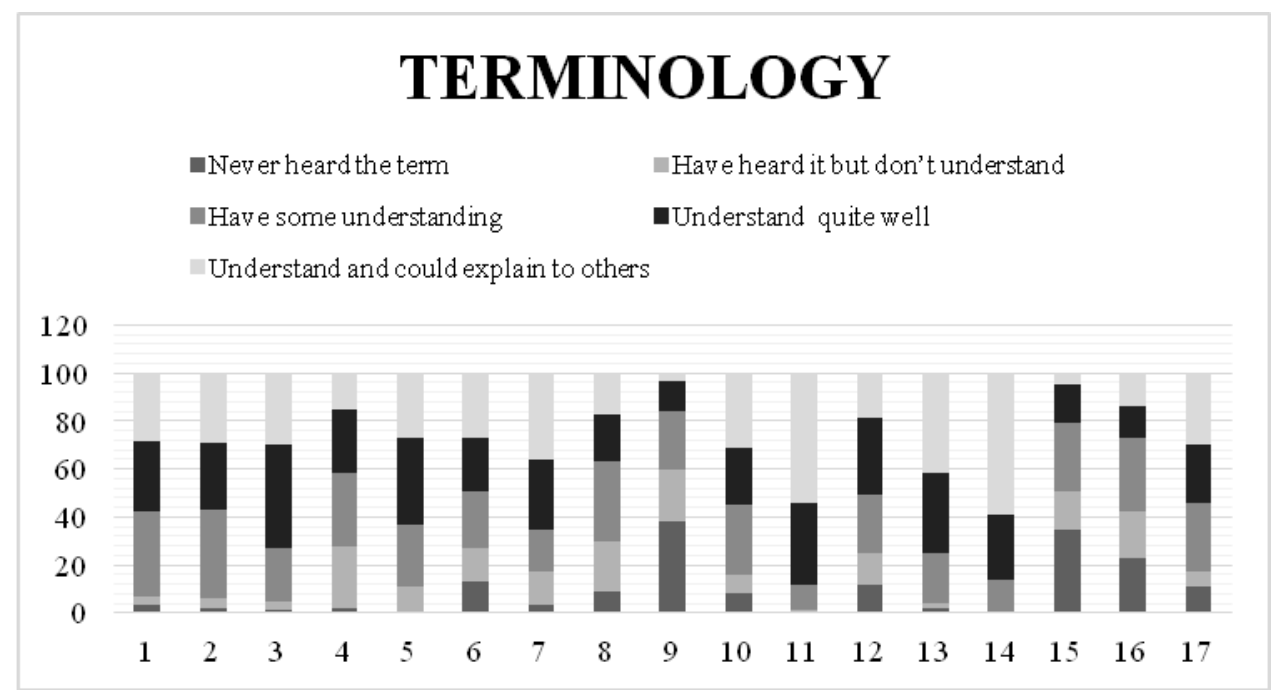

Graph 4: Scoring of responses related to Terminology domain Score (see footnote a)

Footnote a: Terminology

\begin{tabular}{|l|l|}
\hline 1 & Relative risk \\
\hline 2 & Absolute risk \\
\hline 3 & Systematic review \\
\hline 4 & Odds ratio \\
\hline 5 & Meta analysis \\
\hline 6 & Number needed to treat \\
\hline 7 & Confidence interval \\
\hline 8 & Publication bias \\
\hline 9 & Forest plot \\
\hline 10 & Intention to treat \\
\hline 11 & Statistical significance \\
\hline 12 & Minimum clinically worthwhile effect \\
\hline 13 & Clinical importance \\
\hline 14 & Randomised controlled trial (RCT) \\
\hline 15 & Dichotomous outcomes \\
\hline 16 & Continuous outcomes \\
\hline 17 & Treatment effect size \\
\hline
\end{tabular}


Chaitali J. Bhatt et.al. Knowledge, attitude and practice towards evidence based practice in post graduate physiotherapy students.

Graph 5 shows level of confidence in terms of not at all confident and very confident.

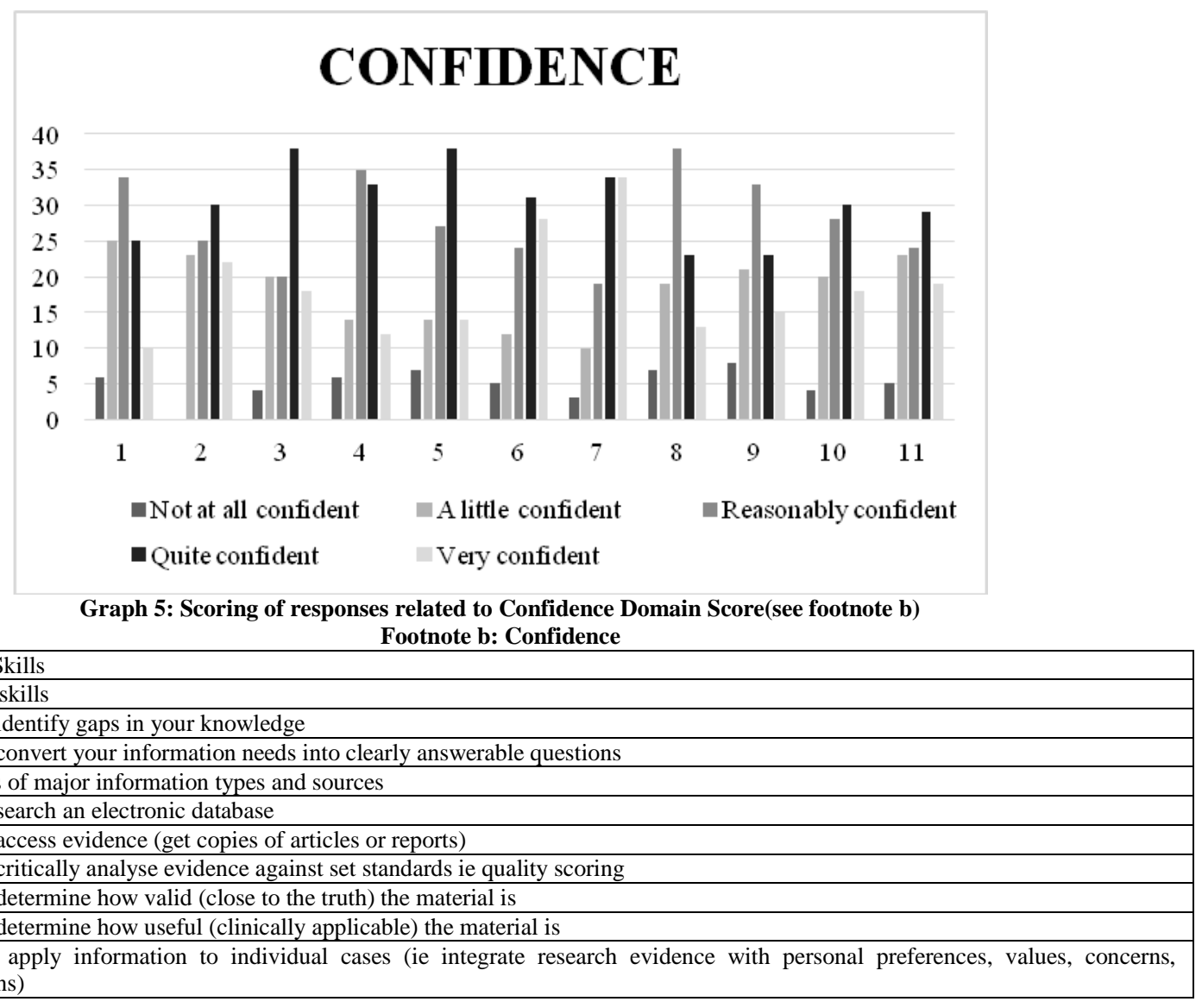

Practice domain refers to the use of EBP in clinical situations. Graph 6 shows percentage score of practice domain of $1^{\text {st }}$ and second year post graduate students.

\section{PRACTICE}

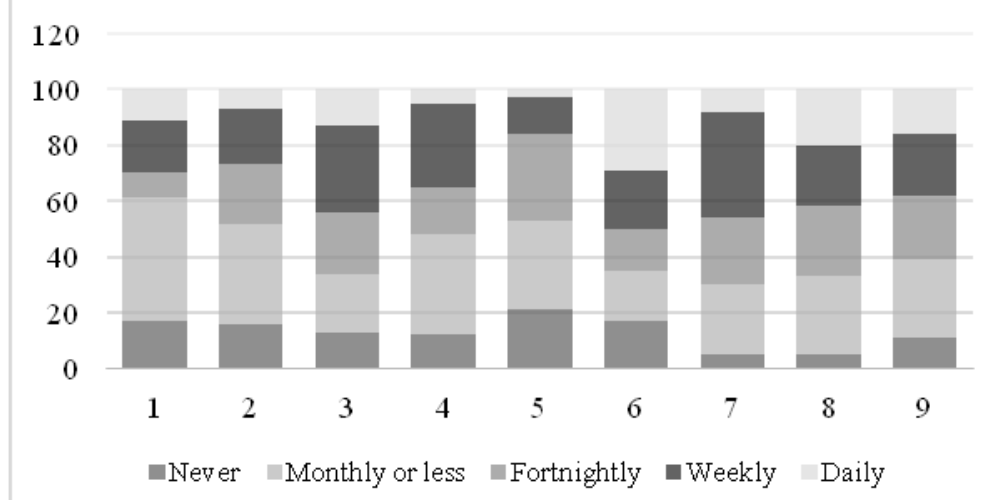

Graph 6: Scoring of responses related to Practice Domain Score (see footnote c)

Footnote c: Practice

\begin{tabular}{|l|l|}
\hline 1 & Formulated a clearly answerable question that defines the client or problem, the intervention and outcome(s) of interest \\
\hline 2 & Tracked down the relevant evidence once you have formulated the question \\
\hline 3 & Searched an electronic database \\
\hline 4 & Critically appraised any literature you have discovered to determine the methodological quality \\
\hline 5 & Integrated research evidence with your expertise \\
\hline 6 & Considered your clients' preferences when making clinical/professional decisions \\
\hline 7 & Read published research reports \\
\hline 8 & Informally shared and discussed literature/research findings with others in your workplace \\
\hline 9 & $\begin{array}{l}\text { Formally shared and discussed literature/research findings with others in your department/practice (eg journal club, in-service } \\
\text { presentation) }\end{array}$ \\
\hline
\end{tabular}


Chaitali J. Bhatt et.al. Knowledge, attitude and practice towards evidence based practice in post graduate physiotherapy students.

Graph 7 shows sympathy domain scores in terms of strongly disagree and strongly agree.

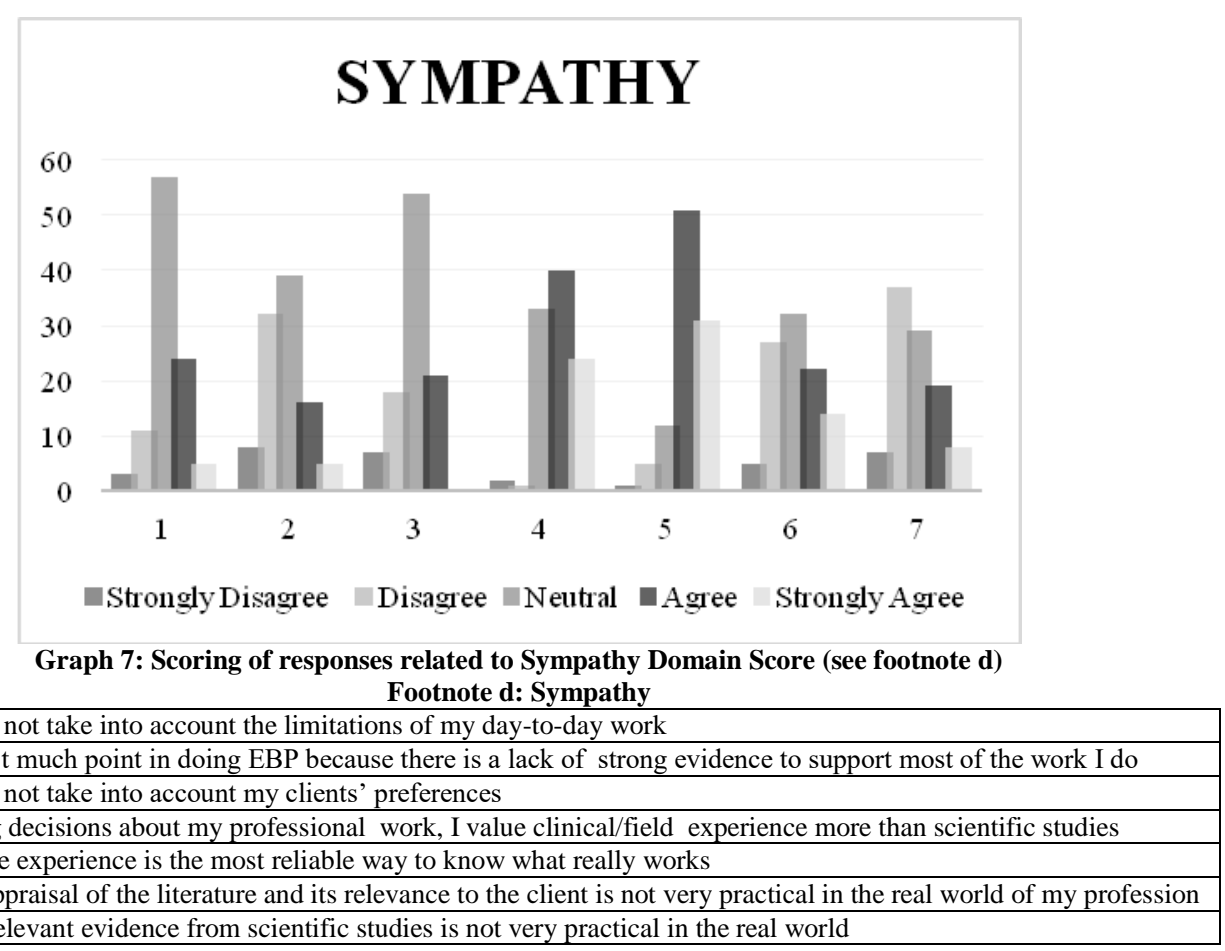

Other 16 non-domain items which describe environmental and personal characteristics were analysed descriptively which is shown in Graph 8.

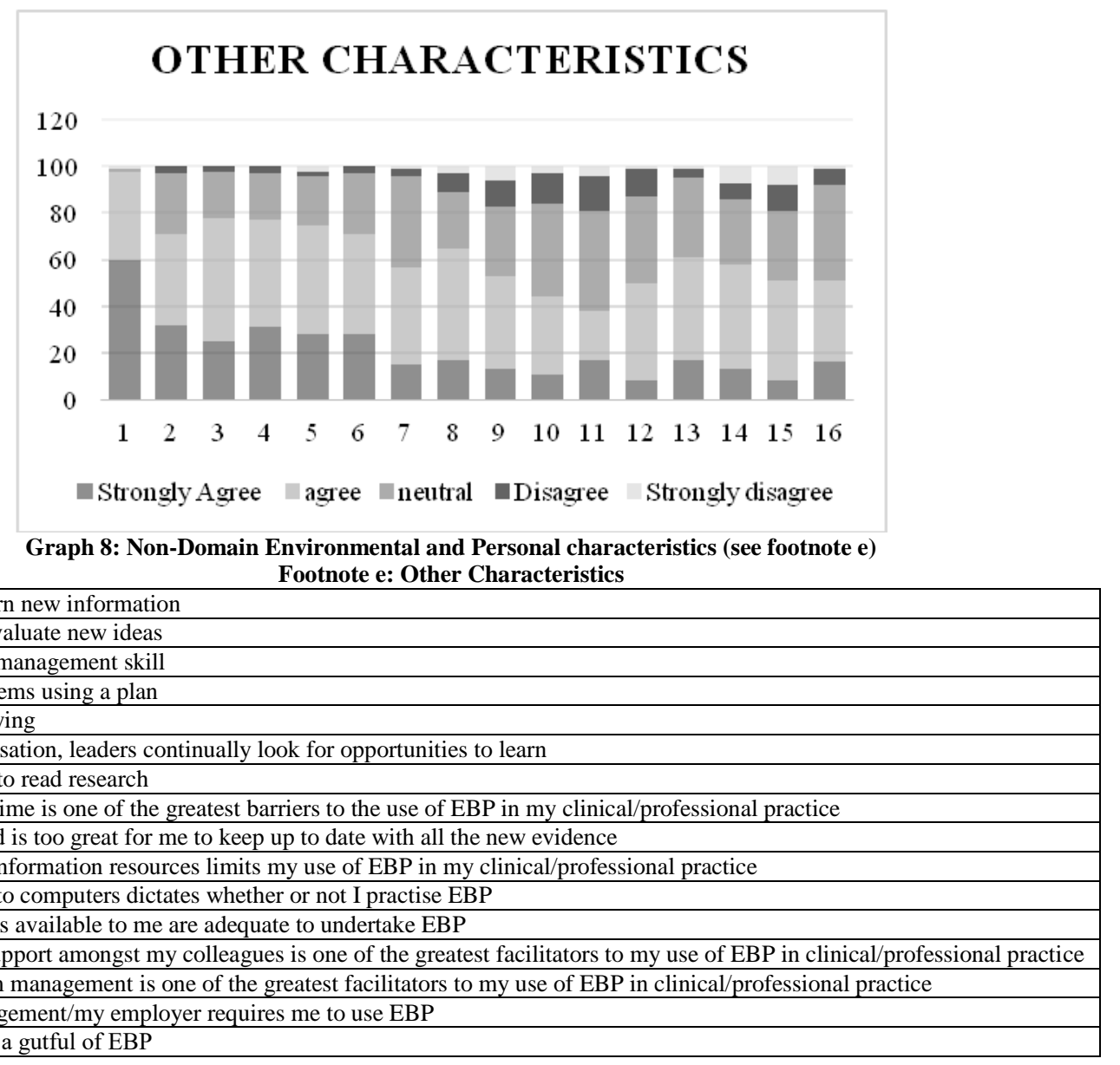


The result of the study shows fair knowledge i.e., in the domain of relevance and terminology, fairly positive attitude i.e., in domain of sympathy and confidence and fair practice i.e., in domain of practice of EBP among Post Graduate students of Gujarat University.

Spearman's correlation was used to find correlation between domains. Correlation values are shown in table 3.

\begin{tabular}{|c|c|c|}
\hline \multicolumn{3}{|c|}{$\begin{array}{l}\text { Table 3: Spearman's correlation value }\left(r_{s}\right) \text { between EBP } \\
\text { domains of Relevance, Terminology, Confidence, Sympathy, } \\
\text { Practice }\end{array}$} \\
\hline Correlation & $\mathbf{r}_{\mathrm{s}}$-value & p value \\
\hline \multicolumn{3}{|l|}{ Relevance - } \\
\hline Terminology & $0.345^{*}$ & $0.001,<0.01$ \\
\hline Confidence & $0.441 *$ & $0.001,<0.01$ \\
\hline Sympathy & 0.047 & 0.644 \\
\hline Practice & $0.223 *$ & $0.026,<0.05$ \\
\hline \multicolumn{3}{|l|}{ Terminology - } \\
\hline Confidence & $0.477 *$ & 0.001 \\
\hline Sympathy & -0.093 & 0.357 \\
\hline Practice & 0.337* & 0.001 \\
\hline \multicolumn{3}{|l|}{ Confidence - } \\
\hline Sympathy & 0.082 & 0.419 \\
\hline Practice & 0.591* & 0.001 \\
\hline Sympathy - Practice & 0.099 & 0.327 \\
\hline
\end{tabular}

\section{DISCUSSION}

The result of the study shows fair knowledge i.e., in the domain of relevance and terminology, fairly positive attitude i.e., in domain of sympathy and confidence and fair practice of EBP among post graduate students of Gujarat University. In the present study $23 \%$ of the students reported they had undertaken EBP training. And out of which $56 \%$ of students taken training in the form of short course of 10-20 hours, $35 \%$ Single lecture 1-3 hours, $9 \%$ of weekend course of 3-10 hours.

$71-83 \%$ of students reported 'highly intend to' or 'absolutely intend to' develop knowledge, skills in accessing, acquiring and appraising evidence relevant to area of practice and to read relevant literature to update knowledge and to apply best available evidence findings to improve practice EBP. In present study, $83 \%$ of students 'agree' or 'strongly agree' need to increase the use of evidence, $89 \%$ of students were interested in learning and improving the skills necessary to incorporate EBP in their work and $73 \%$ reported EBP improves their quality of work. Alshehri, M. A., et al also showed in their study Physiotherapists' awareness and knowledge towards EBP implementation were relatively low, indicating an evident gap in terms of their understanding and application of EBP in Saudi Arabia. ${ }^{[8]}$

Present study shows Spearman's correlation between Relevance and Terminology and Confidence was moderate positive correlation $\left(\mathrm{r}_{\mathrm{s}}=0.345^{*}, \mathrm{r}_{\mathrm{s}}=0.441^{*}\right.$ $\mathrm{p}=0.001,<0.01$ respectively), with Sympathy weak positive correlation $\left(\mathrm{r}_{\mathrm{s}}=\right.$ $0.047, \mathrm{p}=0.644)$, and with Practice was weak positive correlation $\left(\mathrm{r}_{\mathrm{s}}=0.223^{*}, \mathrm{p}=\right.$ $0.026,<0.05)$. Spearman's correlation coefficient between Terminology and Confidence and practice was moderate positive correlation $\left(r_{\mathrm{s}}=0.447, \mathrm{r}_{\mathrm{s}}=0.337 \mathrm{p}\right.$ $<0.001)$, Sympathy negative weak $\left(\mathrm{r}_{\mathrm{s}}=-\right.$ $0.093, \mathrm{p}=0.357)$. There was a positive significant correlation between relevance and terminology with confidence ( $\mathrm{p}<0.01)$.

The present study shows, fair positive attitude with fair knowledge of EBP. The participants were asked for "Do they understand EBP?" and "Do they understand by Relative Risk?" responding Strongly Agree or Strongly Disagree. However, they were not asked to define "What is EBP?" Or "What is Relative Risk?" Manjula R, et al showed in their study on medical students that most of the participants hold positive attitudes toward EBP but lack sufficient knowledge and skills for implementation. ${ }^{[9]}$ In present study, we found fair Knowledge of EBP but we could not assess the knowledge (Terminology, Relevance) descriptively. Similar study by Shaikh, A. A., et al on Physiotherapy students ${ }^{[10]}$, showed there was poor to fair knowledge of Evidence Based Practice.

Alshehri, M. A., et al also showed in their study a positive attitude towards the use of EBP, with most participants responding 'agree' or 'strongly agree' (81$95 \%$ ) with regards to the importance of research in practice. Present study found positive significant correlation between 
relevance and terminology (knowledge) with confidence (Attitude) (p <0.01). Similar result by Alshehri, M. A., et al in their study showed significant association between participants' awareness score and education level $(\mathrm{P}<0.001){ }^{[10]}$

In present study, practice of Routine access to electronic database and reading a published research report daily was found to be $13 \%$ and $8 \%$ which is similar to the results of Manjula $\mathrm{R}$ et al showed $8.2 \%$ participants had daily routine access to database. ${ }^{[9]}$ In the present study fair positive result in attitude to practice EBP domain but $48 \%$ agreed as lack of time as barrier to practice EBP. Similar study by Shaikh, A. A., et al on Physiotherapy students showed ${ }^{10}$ positive attitude to Practice EBP but, they are unable to practice EBP in day to day life reported due to lack of time $(41.8 \%)$ and lack of communication skills. ${ }^{[6,9,10]}$

\section{Limitations}

Only Gujarat university students were included and other characteristics of the students and related questions were not analysed.

\section{CONCLUSION}

The study shows fair knowledge (Relevance, Terminology) of EBP, fairly positive attitude (Sympathy, Confidence), fair practice (Practice) of EBP among post graduate students of Gujarat University.

\section{Implications}

Lack of confidence and fair practice of EBP is seen at post graduate level. So there should be more attention paid to include EBP training in the curriculum and educate the students for EBP training / course at the Graduate level. Incorporating EBP at undergraduate level to improve and encourage practice of EBP in post graduate level and clinical decision making. And thus progress the profession's approach to developing, using and promoting research and its contribution to generating new evidence, knowledge transfer and Health care.

\section{Future Recommendations}

To study the correlation between Knowledge, Attitude and Practice of Evidence Based practice in post graduate students of various university. To compare Knowledge, Attitude and practice level Pre and Post Evidence based practice training in Post graduate students. To study the Knowledge, Attitude and Practice of Evidence Based practice in under graduate students.

\section{ACKNOWLEDGEMENTS}

We are thankful to all participants who helped to complete this study.

\section{Conflict of Interest: None}

\section{Source of Funding: None}

\section{Ethical Approval: Approved}

\section{REFERENCES}

1. Dawes M, Summerskill W, Glasziou P et al Sicily statement on evidence-based practice. BMC Med Ed 2005, 5(1).

2. Sackett DL, Strauss SE et al Evidence-based medicine: how to practice and teach EBM. 2nd ed. Churchill Livingstone, New York2000

3. Taylor Pillae PE.Establishing Evidence Based Practice. Issues and implication in critical care nursing.Intensive care Nursing 1998;14:30-37.

4. Herbert R, Jamtvedt G, Mead j, hagen KB. Practical evidence based Physiotherapy. Butterworth Heinemann,2005;170-197.

5. Glasziou P, Burls A, Gilbert R: Evidence based medicine and the medical curriculum. The search engine is now as essential as the stethoscope. BMJ 2008, 337(a1253):a704a705.

6. WCPT Guidelines [Internet]. Policy Statement: Evidence Based Practice. London: World confederation for physical therapy. 2012 [Updated: Mon 10 Apr 2017]. Available from: www.wcpt.org/policy/psEBP.

7. McEvoy MP, Williams MT, Olds TS: Development and psychometric testing of a trans-professional evidence-based practice profile questionnaire. Med Teach 2010, 32(9):e373-e380. 
Chaitali J. Bhatt et.al. Knowledge, attitude and practice towards evidence based practice in post graduate physiotherapy students.

8. Alshehri, M. A., Alalawi, A., Alhasan, H., \& Stokes, E. (2017). Physiotherapists' behaviour, attitudes, awareness, knowledge and barriers in relation to evidence-based practice implementation in Saudi Arabia: a cross-sectional study. International journal of evidence-based healthcare, 15(3), 127141. doi:10.1097/XEB.0000000000000106

9. Manjula R, Srivastava AK, Dorle AS. Evidence based practice: knowledge, attitude and practice among undergraduate and postgraduate medical students of a medical college in North Karnataka, India.
Int J Community Med Public Health 2018; 5:2411-5.

10. Shaikh, A. A., \& Gad, A. (2017). Evidence based Practice: Knowledge, Attitude and Practice of Physiotherapy Students in Maharashtra. IJPOT, 11(2), 53.

How to cite this article: Bhatt CJ, Sheth MS. Knowledge, attitude and practice towards evidence based practice in post graduate physiotherapy students. Int J Health Sci Res. 2021; 11(8): 17-26. DOI: https://doi.org/10. 52403/ijhsr.20210804

$* * * * * *$ 